\title{
Micropore size analysis in oil-well cement by proton nuclear relaxation Gwenn Le Saoût ${ }^{\mathrm{a}, \mathrm{b}, *}$, Eric Lécolier ${ }^{\mathrm{a}}$, Alain Rivereau ${ }^{\mathrm{a}}$, Hélène Zanni ${ }^{\mathrm{b}}$ \\ anstitut Français du Pétrole, 1-4 av de Bois Préau, 92852 Rueil-Malmaison, France \\ ${ }^{\mathrm{b}}$ Laboratoire de Physique et Mécanique des Milieux Hétérogènes UMR CNRS 7636, ESPCI, 10, rue Vauquelin, 75231 Paris Cedex 05, France
}

\begin{abstract}
The durability of cement depends mainly on cement microstructure parameters such as pore size distribution. In this study, we have observed pore size distribution in a Class $\mathrm{G}$ oil-well cement immersed for 1 year in brine at $T=293 \mathrm{~K}, P=10^{5} \mathrm{~Pa}$ and in a down-hole condition at $T=353 \mathrm{~K}, P=7.10^{6} \mathrm{~Pa}$ by proton nuclear magnetic spin-lattice relaxation ( $\left.{ }^{1} \mathrm{H}-\mathrm{NMR}\right)$. After 4 months of immersion at $T=293 \mathrm{~K}$, $P=10^{5} \mathrm{~Pa}$, the distribution of discrete relaxation rates reveals the fractal feature of the pore size distribution, whereas after 1 year at $T=353 \mathrm{~K}$, $P=7.10^{6} \mathrm{~Pa}$, a dispersed distribution is still observed.
\end{abstract}

Keywords: Oil-well cement; Nuclear magnetic relaxation; Pore size distribution

\section{Introduction}

A frequently used oil-well cement is a Class G cement forming low-viscosity slurry that remains pumpable to considerable depths where elevated temperatures and pressures are almost always encountered. The main role of the cement sheath is to permanently isolate all subsurface formations penetrated by the well. The durability of the cement placed within the wells is of utmost importance and depends mainly on cement microstructure parameters such as porosity. In order to complete the previous structural characterizations of this system [1], porosity has been studied by ${ }^{1} \mathrm{H}$ magnetization relaxation. This nondestructive technique hence allows investigation of both open and closed porosity and previously revealed the hierarchical discrete pore size distribution in cement and concrete [2-4].

\section{Experimental details}

The slurry was prepared with a Class $\mathrm{G}$ Portland cement [Bogue composition (wt\%): $51.2 \mathrm{Ca}_{3} \mathrm{SiO}_{5}, 27 \mathrm{Ca}_{2} \mathrm{SiO}_{4}, 2.3$ $\mathrm{Ca}_{3} \mathrm{Al}_{2} \mathrm{O}_{6}, 14.4 \mathrm{Ca}_{4} \mathrm{Al}_{2} \mathrm{Fe}_{2} \mathrm{O}_{10}$ ] at a water-cement ratio of 0.44 . The mix was cast as $2.10^{-2} \mathrm{~m}$ cubes placed in brine

\footnotetext{
* Corresponding author. Tel.: +33 1407945 56; fax: +33 140794795 E-mail address: lesaout_gwenn@yahoo.fr (G. Le Saoût).
}

for 1 year with two curing temperature and pressure conditions: $T=293 \mathrm{~K}, P=10^{5} \mathrm{~Pa}$ (samples labelled CI in the text) and $T=353 \mathrm{~K}, P=7.10^{6} \mathrm{~Pa}(\mathrm{CII})$.

${ }^{1} \mathrm{H}$ nuclear magnetic spin-lattice relaxation $\left(\mathrm{T}_{1}\right)$ curves were measured with an inversion-recovery method at 100 $\mathrm{MHz}$ in static conditions on a Bruker ASX 100 (Bruker Biospin, Wissembourg, France). Coarse pieces taken in the core of the cement were used in order to limit the water adsorption on the surface of the grains. Previous studies using the fast-exchange model in cement materials clearly evidence nuclear relaxation of protons through hydrated paramagnetic ions such as $\mathrm{Fe}^{3+}$ present at the surface of the pores (see Ref. [4] and references therein).

\section{Results and discussion}

A representative example of the proton magnetization decay is displayed in Fig. 1(A) (CI sample cured for 4 months at $T=293 \mathrm{~K}, P=10^{5} \mathrm{~Pa}$ ). The observed nonexponential longitudinal relaxation decay has been fitted to a sum of single exponentials by the use of two different methods: the graphic curve peeling method [2] and the Laplace inverse transformation using the CONTIN program [5] [Fig. 1(B)]. These two methods were systemically applied to the experimental relaxation data of CI and CII samples cured for 1 month and 1 year and provided practically coinciding five relaxation times spread over five orders of magnitude [Fig. 1(C)]. These relaxation times have been previously 


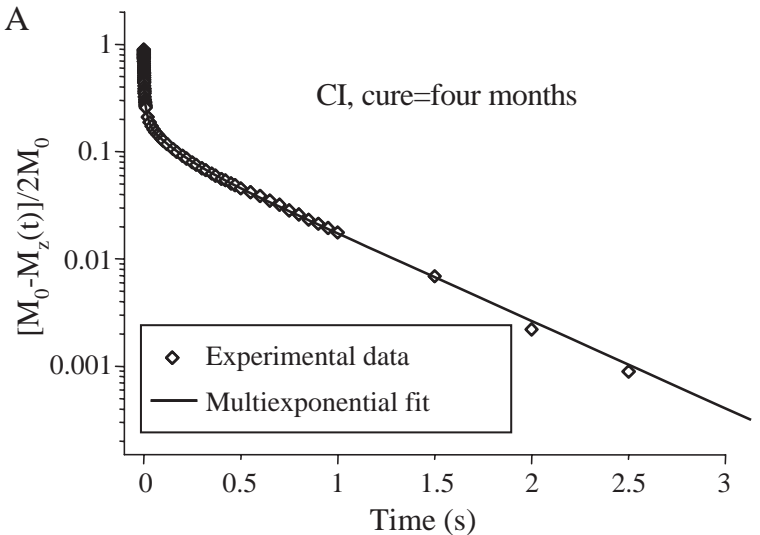

B

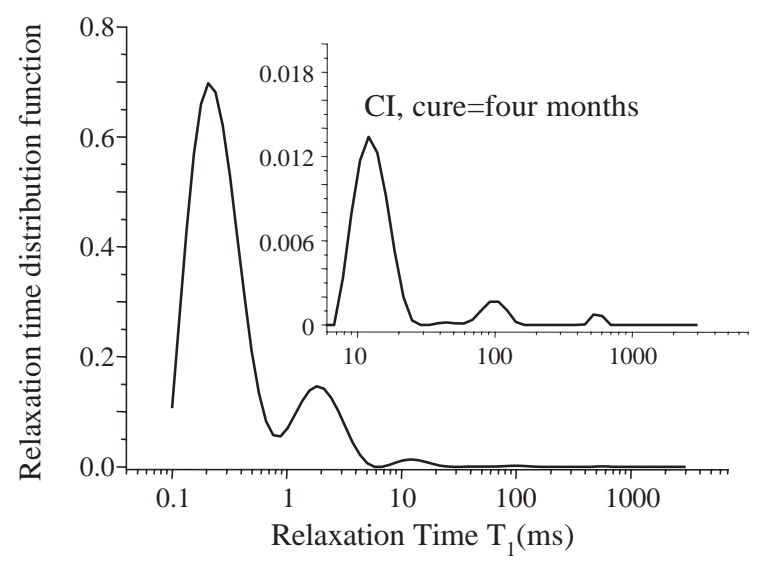

C

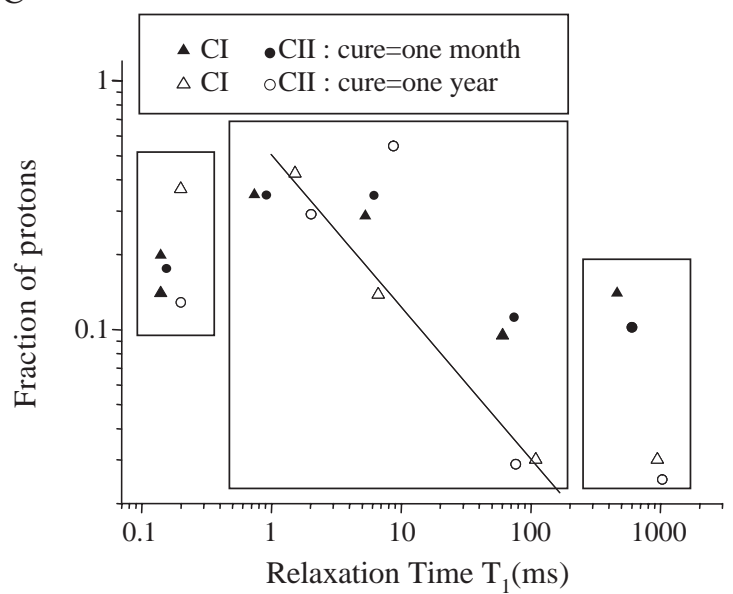

Fig. 1. (A) Recovery of proton longitudinal magnetization at $100 \mathrm{MHz}$ for the CI sample cured for 4 months. (B) Relaxation time distribution function obtained from CONTIN analysis. (C) Logarithmic plot of the fraction of proton magnetization as a function of the longitudinal relaxation time $T_{1}$ for an oil-well cement with different curing conditions.

assessed in cement materials [2-4]: the smaller relaxation time is due to the protons located within hydrates, the second set corresponds to surface protons with various correlation times corresponding to various pore sizes and the longer $T_{1}$ has been assigned to a Portlandite solid-phase $\mathrm{Ca}(\mathrm{OH})_{2}[6]$. In the case of reactive powder cement, the addition of silica fume $\mathrm{SiO}_{2}$ leads to a more Portlandite consumption by a pozzolanic reaction $\left[\mathrm{SiO}_{2}+\mathrm{Ca}(\mathrm{OH})_{2} \rightarrow(\mathrm{CaO})_{\mathrm{x}}, \mathrm{SiO}_{2},\left(\mathrm{H}_{2} \mathrm{O}\right)_{\mathrm{y}}\right]$ and the relative amount of proton attributed to Portlandite may be very weak or absent [2]. For the CI samples, we can notice in the second set of relaxation times a cure time variation from a dispersed distribution up to a power law after 4 months of curing (not shown) characterized by a power exponent, $p$, related to the surface fractal dimension $D_{\mathrm{f}}\left(p=2-D_{\mathrm{f}}\right)$. The power law $\left(D_{\mathrm{f}} \approx 2.4\right.$ at 4 months and $\approx 2.6$ at 1 year) is indicative of the progressive structuration of the pore surface with curing time. This behaviour and the values of $D_{\mathrm{f}}$ are coherent with previous studies $[3,4,7]$. On the contrary, in the CII samples, the distribution still remains dispersed even after 1 year of curing. A previous study [1] on these samples permits to investigate by ${ }^{29} \mathrm{Si}$ NMR the calcium silicate hydrate $(\mathrm{C}-\mathrm{S}-\mathrm{H})$, which is the main constituent of the cement paste. $\mathrm{C}-\mathrm{S}-\mathrm{H}$ presents a poorly crystalline structure with variable composition and is an important source of porosity. We have observed an acceleration of the hydration kinetics and a more polymerised $\mathrm{C}-\mathrm{S}-\mathrm{H}$ with temperature and pressure. The acceleration of the formation of more dense $\mathrm{C}-\mathrm{S}-\mathrm{H}$ around anhydrous particles of cement with temperature and pressure may explain the different pore size distributions of CI and CII samples.

\section{Conclusion}

The pore size distribution in a Class $\mathrm{G}$ oil-well cement cured up to 1 year in brine at $T=293 \mathrm{~K}, P=10^{5} \mathrm{~Pa}$ and $T=353$ $\mathrm{K}, P=7.10^{6} \mathrm{~Pa}$ has been studied by proton nuclear magnetic spin-lattice relaxation. After 4 months of immersion at $T=293 \mathrm{~K}, P=10^{5} \mathrm{~Pa}$, the distribution of discrete relaxation rates reveals the fractal feature of the pore size distribution, whereas after 1 year at $T=353 \mathrm{~K}, P=7.10^{6} \mathrm{~Pa}$, a dispersed distribution is still observed. This behaviour may be explained by a more dense structure of the $\mathrm{C}-\mathrm{S}-\mathrm{H}$ in the cement paste when temperature and pressure increase. In order to have a better characterization of the cement, mechanical test measurements are in progress to try to establish a correlation between the structure and macroscopic properties.

\section{Acknowledgments}

We would like to thank the Institut Français du Pétrole for the permission to publish this paper. We are grateful to Annie Audibert-Hayet for valuable discussions.

\section{References}

[1] Le Saoût G, Lécolier E, Rivereau A, Zanni H. Study of oilwell cements by solid state NMR. C R Chimie 2004;7:383-8.

[2] Korb J-P, Petit D, Philippot S, Zanni H, Maret V, Cheyrezy M. Nuclear relaxation of water confined in reactive powder concrete. In: Zanni $\mathrm{H}$, Soozzani P, editors. Nuclear Magnetic Resonance Spectroscopy of Cement-based Materials. Berlin: Springer; 1998. p. 333-43.

[3] Porteneuve C, Korb J-P, Petit D, Zanni H. Structure-texture correlation in ultra-high-performance concrete: A nuclear magnetic resonance study. Cem Concr Res 2002;32:97-101. 
[4] Plassais A, Pomiès M-P, Lequeux N, Boch P, Korb J-P, Petit D, et al. Micropore size analysis by NMR in hydrated cement. Magn Reson Imaging 2003;21:369-71.

[5] Provencher SW. CONTIN: A general purpose constrained regularization program for inverting noisy linear algebraic and integral equations. Comput Phys Commun 1982;27:229-42.
[6] Schreiner LJ, Mactavish JC, Milkovic L, Pintar MM, Blinc R, Lahajnar $\mathrm{G}$, et al. NMR line shape-spin-lattice relaxation correlation study of Portland cement hydration. J Am Ceram Soc 1985;68:10-6.

[7] Blinc R, Lahajnar G, Zumer S, Pintar MM. NMR study of the time evolution of the fractal geometry of cement gels. Phys Rev B 1988;38:2873-5. 